\title{
Rhinovirus species and tonsillar immune responses
}

\author{
Emilia Mikola ${ }^{1,8^{*}}$ (D), Oscar Palomares ${ }^{2,3,4}$, Riitta Turunen ${ }^{9}$, Matti Waris ${ }^{6,7}$, Lotta E. Ivaska ${ }^{1}$, Antti Silvoniemi ${ }^{1}$, \\ Tuomo Puhakka ${ }^{1,8}$, Beate Rückert ${ }^{2,3}$, Tytti Vuorinen ${ }^{6,7}$, Mübeccel Akdis ${ }^{2,3}$, Cezmi A. Akdis ${ }^{2,3}$ and Tuomas Jartti ${ }^{5}$
}

\begin{abstract}
Background: Rhinovirus $\mathrm{A}$ and $\mathrm{C}$ infections are important contributors to asthma induction and exacerbations. No data exist on the interaction of local immune responses in rhinovirus infection. Therefore, we aimed to determine the tonsillar immune responses according to rhinovirus $\mathrm{A}, \mathrm{B}$ and $\mathrm{C}$ infections.

Methods: We collected tonsillar samples, nasopharyngeal aspirates and peripheral blood from 42 rhinovirus positive tonsillectomy patients. Fifteen respiratory viruses or their types were investigated from nasopharynx and tonsil tissue, and rhinovirus species were typed. The expression of 10 cytokines and 4 transcription factors (IFN- $\alpha$, IFN- $\beta$, IFN- $\gamma$, IL-10, IL-13, IL-17, IL-28, IL-29, IL-37, TGF- $\beta$, FOXP3, GATA3, RORC2 and Tbet) were studied from tonsil tissue by quantitative PCR. A standard questionnaire of respiratory symptoms and health was filled by the patient or his/her guardian. The patients were divided into three groups by the determination of rhinovirus species.

Results: Overall, 16 patients had rhinovirus A, 12 rhinovirus $B$ and 14 rhinovirus $C$ infection. In rhinovirus B positive group there were significantly less men $(P=0.0072)$, less operated in spring $(P=0.0096)$ and more operated in fall $(P=0.030)$ than in rhinovirus $\mathrm{A}$ or $\mathrm{C}$ groups. Rhinovirus $\mathrm{A}$ positive patients had more respiratory symptoms $(P=0.0074)$ and particularly rhinitis $(P=0.036)$ on the operation day. There were no significant differences between the groups in virus codetection. In adjusted analysis, rhinovirus $C$ infections were associated with increased IFN- $a$ $(P=0.045)$ and decreased RORC2 expression $(P=0.025)$.
\end{abstract}

Conclusions: Rhinovirus species associated differently with clinical characteristics and tonsillar cytokine responses.

Keywords: Allergy, Asthma, Children, Cytokine, Rhinovirus, Tonsil

\section{Background}

Human rhinovirus (RV) is a positive-strand RNA-virus in the family Picornaviridae and genus Enterovirus [1, 2]. Three species have been found, A and B in the 1950s and $C$ in 2006 after the development of highly sensitive molecular techniques [1,3]. RV is widely known to be a major cause of common cold and upper respiratory illnesses $[1,4-6]$ but it is also proven to cause lower respiratory diseases $[1,4-6]$. There is evidence that it is a contributor to asthma induction and exacerbations [1, 4-6]. Especially RV-A and RV-C seem to cause more

\footnotetext{
*Correspondence: eamiko@utu.fi

${ }^{8}$ Department of Otorhinolaryngology, Satakunta Central Hospital,

Sairaalantie 3, 28500 Pori, Finland

Full list of author information is available at the end of the article
}

severe respiratory illnesses and are dominate over RV-B in patients with asthma or chronic obstructive pulmonary disease [1, 2, 4, 7]. Moreover RV-A and RV-C are common in hospitalized children $[5,7,8]$.

RV infection causes cell destruction and changes in immunological reactions $[6,8]$. It has influenced the expression of several interferons and cytokines such as IL (interleukin) -4, IL-6, IL-8, IL-13, IL-16 and IFN (interferon) $-\gamma[1,6,8]$. Differences between the immune responses of the three species has not been extensively studied. Jong et al. [9] found no significant differences in the cytokine levels of nasopharyngeal aspirate of RVinfected children but they studied only four cytokines (IFN- $\gamma$, IL-4, IL-10 and tumor necrosis factor $\alpha$ ). It seems that RV-B replicates more slowly and induces less cytokine production than RV-A and RV-C [10]. 
In our previous studies $[11,12]$ we have regarded tonsils as a good in vivo-model for investigating immune responses. Tonsils are local lymphoid tissue and in close contact with infective agents and allergens. In this study our aim was to observe the differences in tonsillar cytokine expression between RV-A, -B and -C species in routine tonsillectomy patients. Most previous studies concern only cytokine expression of nasopharyngeal aspirate in hospitalized patients.

\section{Methods}

\section{Patients}

We enrolled 200 patients who were going through elective tonsillectomy or adenotomy between April 2008 and March 2009 due to clinical indication for the operation in Satakunta Central Hospital, Pori Finland. Written consent to participate in the study from the patient or his/ her guardian was considered as inclusion criteria along with the tonsillectomy. The study protocol was approved by the Ethics Committee of Satakunta Central Hospital.

\section{Study protocol}

From the enrolled patients we collected samples from tonsils, nasopharyngeal aspirate and peripheral blood. The tonsillectomy was performed according to clinical routine. Tonsil samples were cut into $3-4 \mathrm{~mm}$ pieces and stored in RNAlater RNA stabilization reagent (Qiagen, Hilden, Germany), incubated $+4{ }^{\circ} \mathrm{C}$ until next working day and after removal of non-absorbed reagent stored in $-80{ }^{\circ} \mathrm{C}$. Nasopharyngeal aspirates were collected at the beginning of the operation during anesthesia using a standardized procedure [11]. For the viral analysis, part of the tonsil and nasopharyngeal aspirate (NPS) were stored in dry tubes at $-80{ }^{\circ} \mathrm{C}$ [11]. Serum $25(\mathrm{OH})$ $\mathrm{D}$ measurement and serum IgE measurements for food allergen and aeroallergen screening (Phadiatop Combi ${ }^{\circledR}$, Phadia, Uppsala, Sweden) were made from peripheral blood samples. Patient or his/her guardian also filled a standard questionnaire concerning their respiratory symptoms 30 days prior the operation and allergic diseases (Additional file 1: Table S1).

\section{Analysis of viruses and cytokines}

In-house real-time PCR was used to detect enterovirus (EV), human bocavirus-1 (HBoV-1), respiratory syncytial virus (RSV) and RV [11]. For detection of adenovirus $(\mathrm{AdV})$, coronavirus $(\mathrm{CoV})$, influenza $\mathrm{A}$ and $\mathrm{B}$ viruses (Flu A and B), metapneumovirus (MPV), parainfluenza virus types $1-3$ (PIV 1-3), RSV group $A$ and $B$, and RV Seeplex RV12 ACE detection multiplex PCR assay was used (Seegene, Seoul, Korea) [11, 13]. Virus diagnostics were performed in the Department of Virology, University of Turku, Turku, Finland, and in the Department of
Clinical Microbiology, Karolinska University Hospital, Stockholm, Sweden. Rhinovirus typing was made by amplifying and sequencing the partial VP4/VP2 and 5' non coding region of RV genome $[14,15]$.

Previously stabilized tonsil tissue were homogenized in grinding tubes containing CK28 ceramic beads by using a Precellys 24 homogenizer (Bertin Technologies, Montigny le Bretonneux, France) two times at $6000 \mathrm{rpm}$ for $50 \mathrm{~s}$ [11]. Total RNA was then isolated using the RNeasy mini kit (Qiagen, Hilden, Germany). Reverse transcription was performed with the Revert Aid M-MuLV Reverse Transcriptase (Fermentas, St. Leon-Rot, Germany) using random hexamer primers according to the manufacturers protocol. Gene expression of IFN- $\alpha$, IFN- $\beta$, IFN- $\gamma$, IL-10, IL-13, IL-17, IL-28, IL-29, IL-37, TGF- $\beta$ (tumour growth factor $\beta$ ), FOXP3 (forkhead box protein 3), GATA3 (GATA-binding factor 3), RORC2 (RAR-related orphan receptor C 2) and Tbet (T-box transcription factor) were analyzed by quantitative real-time PCR using iTaq SYBR Green Supermix with ROX (Bio-Rad, Hercules, CA, USA) on a 7900HT Fast Real-Time PCR instrument (Applied Biosystems, Foster City, CA, USA). Housekeeping elongation factor $1 \alpha(E F 1 \alpha)$ was used for normalization. Data are shown as relative expressions, which show $2^{-}$ $(\Delta \mathrm{CT})$ values multiplied by $10^{4}$, where $\Delta \mathrm{CT}$ corresponds to the difference between the CT value for the gene of interest and EF1 $\alpha[11,12]$.

\section{Statistical analysis}

Data was analyzed using JMP Pro version 12.0.1 software (SAS Institute Inc. Cary, NC, USA). Due to skewed distribution continuous variables are described as medians and interquartile ranges and were analyzed using Kruskal-Wallis test. Categorical variables are expressed as frequencies and percentages and were analyzed using Chi square test or Fisher's exact test (when counts $<5$ ). Before regression analyses, cytokine and transcription factor values were log-transformed because of positively skewed distributions. Clinical, viral and immunological differences between study groups were analyzed using unadjusted and multivariable linear model analysis. The adjustments for immunologic analyses included clinical factors and virus infections which significantly differed between the groups (sex, season of the surgery spring or fall, any respiratory symptoms on the operation day, rhinitis on the operation day) and age. Backward stepwise method was used for the final adjustment model separately for each cytokine and transcription factor. Only statistically significant factors were kept in the model. $P<0.05$ was considered statistically significant. 


\section{Results}

\section{Recruitment and study population}

Of 200 patients 143 had viral and immunological analyzes made from their tonsils. Fifty-seven patients were excluded because of poor quality of tonsil samples (Fig. 1). Of those 143 patients, fifty-seven samples were rhinovirus positive in primary PCR test. Of them rhinovirus sequencing was successful from 42 samples (Fig. 1).

\section{Patient characteristics}

Median age of study subjects was 9.3 years, $55 \%$ were males, and $42 \%$ had food or aeroallergen sensitization (Table 1). Main indications for tonsillectomy were tonsillar hypertrophy in $43 \%$ subjects and recurrently infected tonsils in $19 \%$ subjects (Table 1). RV-A and -C groups had male dominance. RV-A epidemic occurred in spring and RV-C epidemics in fall, and RV-A infected subjects were most often symptomatic (Table 1).

\section{Viral findings}

Sixteen (38\%) patients had positive RV-A, 12 (29\%) positive RV-B and 14 (33\%) positive RV-C detection in NPS (Table 2). Most common virus codetections were $\mathrm{HBoV}-1$ (19\%), AdV (7\%), CoV (7\%) in NPS and HBoV-1(17\%),
AdV (10\%), EV (10\%), PIV 1-3 (7\%) in tonsils (Table 2). Other codetections in NPS were EV, Flu A or B, PIV 1-3 and RSV and in tonsils CoV, MPV and RSV (all $<5 \%$ ). In tonsils RV was found from one patient in each group. There were no statistically significant differences in virus codetection between the RV species (Table 2).

\section{Cytokines and transcription factors}

Table 3 presents the expression rates of cytokines and transcription factors, including T-helper ${ }_{1}$, T-helper ${ }_{2}$, T-helper ${ }_{17}$ and T-regulatory type cytokines and transcription factors and type I/III interferons. In adjusted analysis, the highest IFN- $\alpha$ expression and the lowest RORC2 expression were associated with RV-C detection (both $P<0.05$ for overall differences) (Figs. 2 and 3). RV-B detection was associated with lowest Tbet expression ( $P=0.056$ for overall differences) (Fig. 4). Otherwise, no significant differences or tendencies were found (Table 3).

\section{Discussion}

The clinical consequences of rhinovirus $\mathrm{A}, \mathrm{B}$ and $\mathrm{C}$ infections have previously been proven to differ from each other [1]. Thus, it is evident that immunological responses due to these distinct species are diverse.

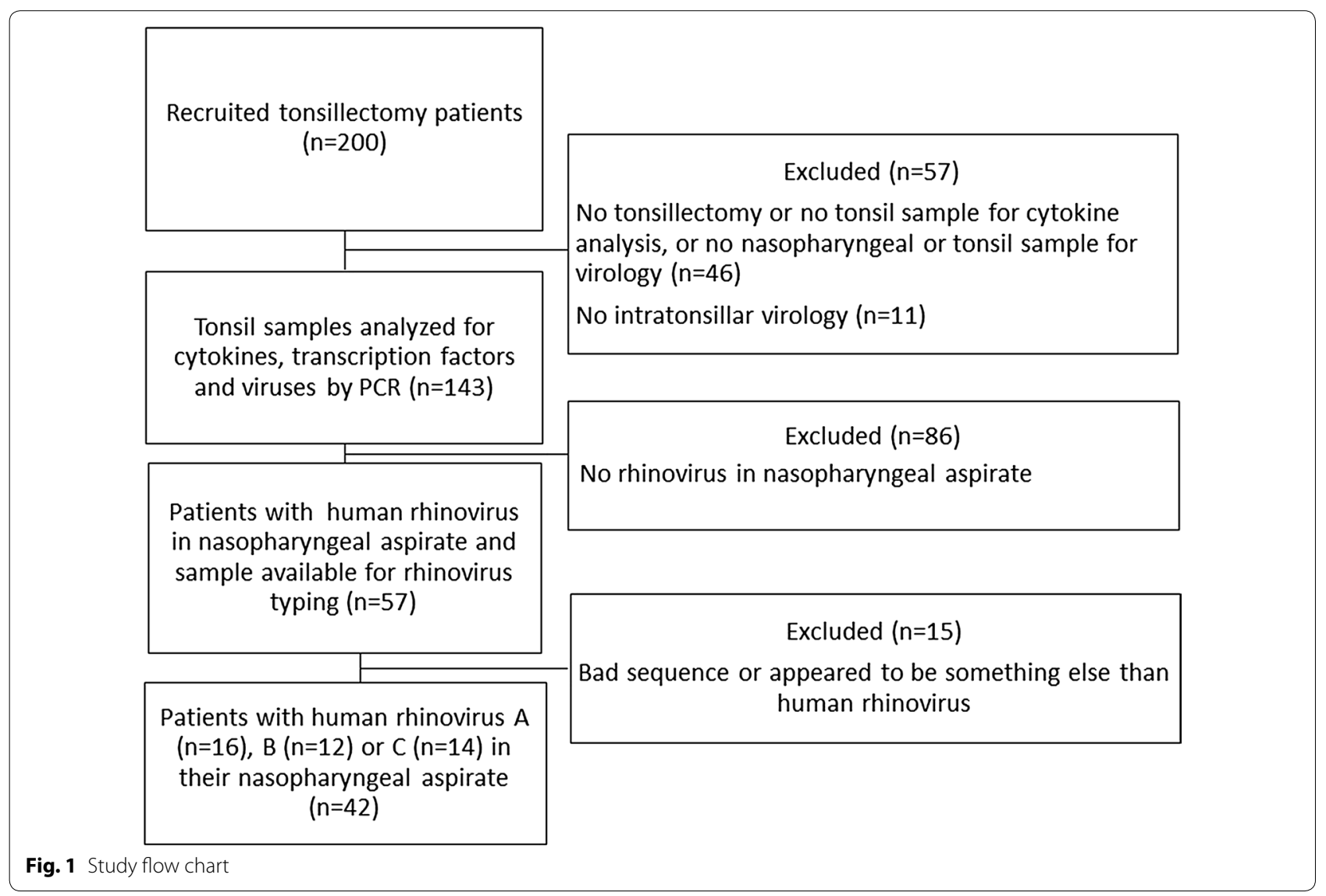


Table 1 Patient characteristics

\begin{tabular}{|c|c|c|c|c|c|}
\hline Characteristics & All, $n=42$ & $R V-A, n=16$ & RV-B, $n=12$ & $R V-C, n=14$ & $P$ value \\
\hline Age, years & $9.3(2.6,40)$ & $9.1(2.6,17)$ & $13.3(4.8,36)$ & $8.5(3.2,40)$ & 0.38 \\
\hline Male & $23(55 \%)$ & $11(69 \%)$ & $2(17 \%)$ & $10(71 \%)$ & 0.0072 \\
\hline Tonsillectomy and adenotomy & $22(52 \%)$ & $9(56 \%)$ & $6(50 \%)$ & $7(50 \%)$ & 0.93 \\
\hline Self-smoking & $1 / 41(2 \%)$ & $0(0 \%)$ & $1(8.3 \%)$ & 0/13 (0\%) & 0.29 \\
\hline Maternal smoking & 16/41 (39\%) & $6(38 \%)$ & $4 / 11(36 \%)$ & $6(43 \%)$ & 1.0 \\
\hline Paternal smoking & 17/37 (46\%) & $5 / 15(33 \%)$ & $5 / 10(50 \%)$ & $7 / 12(58 \%)$ & 0.42 \\
\hline \multicolumn{6}{|l|}{ Season of the surgery } \\
\hline Winter (months 12-2) & $4(9.5 \%)$ & $0(0 \%)$ & $3(25 \%)$ & $1(7.1 \%)$ & 0.057 \\
\hline Spring (months 3-5) & $11(26 \%)$ & $8(50 \%)$ & $0(0 \%)$ & $3(21 \%)$ & 0.0096 \\
\hline Summer (months 6-8) & $6(14 \%)$ & $4(25 \%)$ & $0(0 \%)$ & $2(14 \%)$ & 0.21 \\
\hline Fall (months 9-11) & $21(50 \%)$ & $4(25 \%)$ & $9(75 \%)$ & $8(57 \%)$ & 0.030 \\
\hline \multicolumn{6}{|l|}{ Indication of the surgery } \\
\hline Obstruction only & $18(43 \%)$ & $5(31 \%)$ & $6(50 \%)$ & $7(50 \%)$ & 0.49 \\
\hline Recurrent tonsillitis only & $8(19 \%)$ & $2(13 \%)$ & $2(17 \%)$ & $4(29 \%)$ & 0.55 \\
\hline Obstruction + tonsillitis & $7(17 \%)$ & $3(19 \%)$ & $2(17 \%)$ & $2(14 \%)$ & 1.0 \\
\hline Other & $9(21 \%)$ & $6(38 \%)$ & $2(17 \%)$ & $1(7.1 \%)$ & 0.14 \\
\hline Respiratory symptoms on operation day & 13/39 (33\%) & $10(63 \%)$ & $1 / 10(10 \%)$ & $2 / 13(15 \%)$ & 0.0074 \\
\hline Throat pain & $3 / 39(7.7 \%)$ & $2(13 \%)$ & $0 / 10$ & $1 / 13(7.7 \%)$ & 0.77 \\
\hline Cough & $6 / 39(15 \%)$ & $4(25 \%)$ & $1 / 10(10 \%)$ & $1 / 13(7.7 \%)$ & 0.53 \\
\hline Acute otitis media & $0 / 39(0 \%)$ & $0(0 \%)$ & $0 / 10(0 \%)$ & 0/13 (0\%) & - \\
\hline Wheezing & $0 / 39(0 \%)$ & $0(0 \%)$ & $0 / 10(0 \%)$ & 0/13 (0\%) & - \\
\hline Other & $1 / 39(2.6 \%)$ & $1(6.3 \%)$ & 0/10 (0\%) & 0/13 (0\%) & 1.0 \\
\hline Respiratory symptoms within 2 weeks & 18/34 (53\%) & 10/15 (67\%) & $4 / 8(50 \%)$ & $4 / 11(36 \%)$ & 0.34 \\
\hline Respiratory symptoms within 4 weeks & $22 / 34(65 \%)$ & $11 / 15(73 \%)$ & $5 / 8(63 \%)$ & $6 / 11(55 \%)$ & 0.66 \\
\hline Total 25-OHD (nmol/l) & $54(45,66)$ & $54(48,68)$ & $51(38,64)$ & $58(41,69)$ & 0.72 \\
\hline Free & $7.2(5.3,8.2)$ & $7.0(5.7,10)$ & $6.5(4.3,7.9)$ & $7.3(5.3,8.5)$ & 0.69 \\
\hline Bioavailable & $2.4(1.9,3.0)$ & $2.5(2.0,4.0)$ & $2.1(1.6,2.7)$ & $2.4(1.8,3.3)$ & 0.45 \\
\hline Self-reported allergy & $18(43 \%)$ & $6(38 \%)$ & $7(58 \%)$ & $5(36 \%)$ & 0.44 \\
\hline Physician-diagnosed atopic dermatitis & $7 / 41(17 \%)$ & $1(6.3 \%)$ & $4(33 \%)$ & $2 / 13(15 \%)$ & 0.19 \\
\hline Self-reported allergic rhinitis & $10 / 40(25 \%)$ & $4(25 \%)$ & $4 / 11(36 \%)$ & $2 / 13(15 \%)$ & 0.53 \\
\hline Physician-diagnosed asthma & $8 / 40(20 \%)$ & $1 / 15(6.7 \%)$ & $5(42 \%)$ & 2/13 (15\%) & 0.099 \\
\hline Sensitization & 14/33 (42\%) & $3 / 11(27 \%)$ & $5 / 9(56 \%)$ & 6/13 (46\%) & 0.45 \\
\hline Food & 4/33 (12\%) & 1/11 (9.1\%) & 0/9 (0\%) & $3 / 13(23 \%)$ & 0.42 \\
\hline Aeroallergen & $11 / 33(33 \%)$ & 2/11 (18\%) & $5 / 9(56 \%)$ & 4/13 (31\%) & 0.25 \\
\hline
\end{tabular}

25-OHD, 25-hydroxyvitamin D

Data are expressed as median (range), or number of subjects (\%)

Bearing these things in mind, we conducted our study with routine tonsillectomy patients, which has three main findings. First, rhinovirus species A, B and C were rather equally distributed among relatively asymptomatic tonsillectomy patients and were mainly found in nasopharyngeal aspirate compared to the low persistence rate in tonsils. Second, rhinovirus species were differently associated with tonsillar cytokine responses. Rhinovirus $C$ affected patients had increased IFN- $\alpha$ and decreased RORC2 expression in tonsils when compared to other rhinovirus species (Figs. 2 and 3). Third, rhinovirus species were differently associated with clinical characteristics.

The similar incidence rates of RV species was a bit unexpected since RV-B has usually been slightly less prevalent than RV-A and RV-C in healthy subjects $[5,7$, 8]. However, this difference has been more pronounced in children with severe wheezing and asthma, in whom $\mathrm{RV}-\mathrm{A}$ and RV-C species have also associated with more severe symptoms $[2,7,8]$. Our children study subjects were rather young (median 9 years old) and generally healthy which is likely to favor more equal distribution 
Table 2 Virus detection

\begin{tabular}{|c|c|c|c|c|c|c|c|c|}
\hline \multirow[t]{2}{*}{ Virus } & \multicolumn{3}{|c|}{ Nasopharynx } & \multirow[t]{2}{*}{$P$ value } & \multicolumn{3}{|l|}{ Tonsil } & \multirow[t]{2}{*}{$P$ value } \\
\hline & RV-A $n=16$ & $\begin{array}{l}\text { RV-B } \\
n=12\end{array}$ & $R V-C n=14$ & & $\begin{array}{l}\text { RV-A } \\
n=16\end{array}$ & $\begin{array}{l}\text { RV-B } \\
n=12\end{array}$ & $\begin{array}{l}R V-C \\
n=14\end{array}$ & \\
\hline Adenovirus & $1(6.3 \%)$ & $2(17 \%)$ & $0(0 \%)$ & 0.27 & $3(19 \%)$ & $0(0 \%)$ & $1(7.1 \%)$ & 0.36 \\
\hline Bocavirus-1 & $2(13 \%)$ & $3(25 \%)$ & $3(21 \%)$ & 0.70 & $5(31 \%)$ & $1(8.3 \%)$ & $1(7.1 \%)$ & 0.22 \\
\hline Coronavirus & $3(19 \%)$ & $0(0 \%)$ & $0(0 \%)$ & 0.10 & $1(6.3 \%)$ & $0(0 \%)$ & $0(0 \%)$ & 1.0 \\
\hline Enterovirus & $1(6.3 \%)$ & $0(0 \%)$ & $0(0 \%)$ & 1.0 & $1(6.3 \%)$ & $1(8.3 \%)$ & $2(14 \%)$ & 0.82 \\
\hline Influenza A or B virus & $1(6.3 \%)$ & $0(0 \%)$ & $0(0 \%)$ & 1.0 & $0(0 \%)$ & $0(0 \%)$ & $0(0 \%)$ & - \\
\hline Metapneumovirus & $0(0 \%)$ & $0(0 \%)$ & $0(0 \%)$ & - & $1(6.3 \%)$ & $0(0 \%)$ & $0(0 \%)$ & 1.0 \\
\hline Parainfluenza virus types $1-3$ & $2(13 \%)$ & $0(0 \%)$ & $0(0 \%)$ & 0.32 & $2(13 \%)$ & $0(0 \%)$ & $1(7.1 \%)$ & 0.77 \\
\hline Respiratory syncytial virus & $1(6.3 \%)$ & $0(0 \%)$ & $0(0 \%)$ & 1.0 & $1(6.3 \%)$ & $0(0 \%)$ & $0(0 \%)$ & 1.0 \\
\hline Rhinovirus & $16(100 \%)$ & $12(100 \%)$ & $14(100 \%)$ & - & $1(6.3 \%)$ & $1(8.3 \%)$ & $1(7.1 \%)$ & 1.0 \\
\hline \multicolumn{9}{|l|}{ Number of positive viruses } \\
\hline 1 virus & $8(50 \%)$ & $8(67 \%)$ & $11(79 \%)$ & 0.26 & $4(25 \%)$ & $1(8.3 \%)$ & $6(43 \%)$ & 0.15 \\
\hline 2 viruses & $5(31 \%)$ & $3(25 \%)$ & $3(21 \%)$ & 0.91 & $2(13 \%)$ & $1(8.3 \%)$ & $0(0 \%)$ & 0.49 \\
\hline 3 viruses & $3(19 \%)$ & $1(8.3 \%)$ & $0(0 \%)$ & 0.29 & $1(6.3 \%)$ & $0(0 \%)$ & $0(0 \%)$ & 1.0 \\
\hline 4 viruses & $0(0 \%)$ & $0(0 \%)$ & $0(0 \%)$ & - & $1(6.3 \%)$ & $0(0 \%)$ & $0(0 \%)$ & 1.0 \\
\hline$\geq 1$ viruses & $16(100 \%)$ & $12(100 \%)$ & $14(100 \%)$ & - & $8(50 \%)$ & $2(17 \%)$ & $6(43 \%)$ & 0.18 \\
\hline$\geq 2$ viruses & $8(50 \%)$ & $4(33 \%)$ & $3(21 \%)$ & 0.26 & $4(25 \%)$ & $1(8.3 \%)$ & $0(0 \%)$ & 0.11 \\
\hline$\geq 3$ viruses & $3(19 \%)$ & $1(8.3 \%)$ & $0(0 \%)$ & 0.29 & $2(13 \%)$ & $0(0 \%)$ & $0(0 \%)$ & 0.32 \\
\hline$\geq 4$ viruses & $0(0 \%)$ & $0(0 \%)$ & $0(0 \%)$ & - & $1(6.3 \%)$ & $0(0 \%)$ & $0(0 \%)$ & 1.0 \\
\hline
\end{tabular}

Data are expressed as number of subjects (\%)

of RV species. Symptomatic and asymptomatic infections are also more common in children than in adults $[1,11]$.

We found no difference between rhinovirus $\mathrm{A}, \mathrm{B}$ or $\mathrm{C}$ positive tonsillectomy patients in terms of viral coinfections. It has been shown that viral codetection is common especially in children [16, 17]. Morikawa et al. [16] noted that the coinfection rates of RV-A and C are high, but it remains unclear whether they found differences between the coinfection rates of RV-A, RV-B and RV-C. Miller et al. [18] found more coinfections with RV-A than with RV-C in hospitalized children. We found male sex to be dominant in RV-A and RV-C infected patients. This is in line with a previous study with male sex dominating in RV-A and RV-C infections in hospitalized children [14]. Reason for that might be in sex hormones as androgens promote Th1 (T helper type 1 cell) responses and estrogen and progesterone Th2 responses [19]. The seasonality of all the rhinovirus types seemed to follow the seasonality described in literature $[2,8,16,20,21]$ : there was a major peak in fall and a smaller peak in spring, but the rhinoviruses were detected throughout the whole year. $\mathrm{RV}-\mathrm{C}$ and RV-B were found mostly from patients operated in fall whereas RV-A was most commonly found in spring.

The most interesting and novel finding was the higher level of tonsillar IFN- $\alpha$ production in patients with $\mathrm{RV}-\mathrm{A}$ and RV-C infection, especially in those with RV-C, compared with RV-B infected patients. Type I interferons, including IFN- $\alpha$, are important antiviral cytokines and for preventing inappropriate Th2 response $[8,22]$. Considering the ability of RV-A and RV-C to cause more severe infection than RV-B $[1,2]$, it is plausible that they may also induce stronger interferon responses. In fact, strong IFN- $\gamma$ responses have been associated with reduced virus shedding, and exposure to IFN- $\alpha$ or IFN- $\gamma$ has limited RV infection in vitro [6, 21]. Our findings are in agreement with these previous findings and extend the increased expression of type I interferon to local lymphoid tissue level in healthy individuals. Moreover, some previous findings suggest that RV-C may cause slightly more severe infection than RV-A [1] which also fit to our finding.

In addition, we found a close to significant difference between the Tbet expressions in tonsils of the patients harboring distinct RV species (Fig. 4). The level of expression was highest in patients with RV-A infection and lowest in those with RV-B infection. Tbet controls the differentation of Th1 cells and acts together with RUNX3 (runt-related transcription factor) to induce IFN- $\gamma$ production [23]. Glanville et al. [24] found Tbet deficient mice to develop Th2 and Th17 responses to RV infection instead of Th1 responses. They also found Tbet deficient mice to develop significant eosinophilia and mucus production after RV infection. Our finding on Tbet is in agreement with previous experimental 
Table 3 Cytokine or transcription factor expression

\begin{tabular}{|c|c|c|c|c|c|c|}
\hline $\begin{array}{l}\text { Cytokine or } \\
\text { transcription } \\
\text { factor }\end{array}$ & $\begin{array}{l}\text { RV-A } \\
n=16\end{array}$ & $\begin{array}{l}\text { RV-B } \\
n=12\end{array}$ & $\begin{array}{l}R V-C \\
n=14\end{array}$ & $\begin{array}{l}P \text { value } \\
\text { univariate }\end{array}$ & $\begin{array}{l}P \text { value } \\
\text { multivariate }\end{array}$ & Adjustments \\
\hline \multicolumn{7}{|l|}{ Th 1 -type } \\
\hline $\mathrm{IFN}-\gamma$ & $\begin{array}{l}71^{*} \\
(27,104)\end{array}$ & $\begin{array}{l}58 \\
(34,72)\end{array}$ & $\begin{array}{l}72 \\
(33,98)\end{array}$ & 0.99 & 0.61 & Spring \\
\hline Tbet & $\begin{array}{l}72 \\
(27,309)\end{array}$ & $\begin{array}{l}33 \\
(15,60)\end{array}$ & $\begin{array}{l}40 \\
(15,70)\end{array}$ & 0.082 & 0.056 & Respiratory symptoms, spring \\
\hline \multicolumn{7}{|l|}{$\mathrm{Th}_{2}$-type } \\
\hline IL-13 & $\begin{array}{l}0.40 \\
(0.018,5.0)\end{array}$ & $\begin{array}{l}0.37 \\
(0.020,3.4)\end{array}$ & $\begin{array}{l}1.8 \\
(0.36,7.6)\end{array}$ & 0.14 & 0.14 & - \\
\hline GATA3 & $\begin{array}{l}31 \\
(13,50)\end{array}$ & $\begin{array}{l}20 \\
(6.2,33)\end{array}$ & $\begin{array}{l}21 \\
(12,37)\end{array}$ & 0.36 & 0.98 & Spring \\
\hline \multicolumn{7}{|l|}{$\mathrm{Th}_{17}$-type } \\
\hline $\mid \mathrm{LL}-17$ & $\begin{array}{l}15 \\
(9.1,26)\end{array}$ & $\begin{array}{l}14 \\
(3.8,26)\end{array}$ & $\begin{array}{l}8.0 \\
(4.0,14)\end{array}$ & 0.37 & 0.36 & Age \\
\hline $\mathrm{RORC2}$ & $\begin{array}{l}22 \\
(9.7,71)\end{array}$ & $\begin{array}{l}18 \\
(7.2,29)\end{array}$ & $\begin{array}{l}14 \\
(6.2,25)\end{array}$ & 0.31 & 0.025 & Respiratory symptoms \\
\hline \multicolumn{7}{|l|}{ Treg -type } \\
\hline$\| \mathrm{L}-10$ & $\begin{array}{l}55 \\
(32,84)\end{array}$ & $\begin{array}{l}40 \\
(14,62)\end{array}$ & $\begin{array}{l}33 \\
(22,74)\end{array}$ & 0.34 & 0.96 & Age, spring \\
\hline IL-37 & $\begin{array}{l}0.38 \\
(0.14,0.50)\end{array}$ & $\begin{array}{l}0.22^{* *} \\
(0.14,0.34)\end{array}$ & $\begin{array}{l}0.27 \\
(0.14,0.34)\end{array}$ & 0.64 & 0.11 & Respiratory symptoms \\
\hline FOXP3 & $\begin{array}{l}56 \\
(19,107)\end{array}$ & $\begin{array}{l}33 \\
(13,89)\end{array}$ & $\begin{array}{l}29 \\
(16,88)\end{array}$ & 0.47 & 0.12 & Rhinitis \\
\hline TGF- $\beta$ & $\begin{array}{l}146 \\
(94,185)\end{array}$ & $\begin{array}{l}192 \\
(108,252)\end{array}$ & $\begin{array}{l}139 \\
(102,187)\end{array}$ & 0.49 & 0.49 & - \\
\hline \multicolumn{7}{|c|}{ Type I/III interferons } \\
\hline IFN-a & $\begin{array}{l}5.8 \\
(0,44)\end{array}$ & $\begin{array}{l}0.37^{* *} \\
(0.33,38)\end{array}$ & $\begin{array}{l}22 \\
(2.9,78)\end{array}$ & 0.23 & 0.045 & Respiratory symptoms \\
\hline IFN- $\beta$ & $\begin{array}{l}15 \\
(3.3,81)\end{array}$ & $\begin{array}{l}4.9 \\
(2.2,68)\end{array}$ & $\begin{array}{l}61 \\
(7.7,116)\end{array}$ & 0.30 & 0.30 & - \\
\hline IL-28 & $\begin{array}{l}25^{*} \\
(1.4,88)\end{array}$ & $\begin{array}{l}9.7 \\
(1.4,62)\end{array}$ & $\begin{array}{l}32 \\
(13,109)\end{array}$ & 0.41 & 0.41 & - \\
\hline IL-29 & $\begin{array}{l}5.9 \\
(1.3,35)\end{array}$ & $\begin{array}{l}3.1 \\
(1.3,22)\end{array}$ & $\begin{array}{l}11 \\
(4.4,40)\end{array}$ & 0.53 & 0.53 & - \\
\hline
\end{tabular}

IFN interferon, Tbet T-box transcription factor, IL interleukin, GATA3 GATA-binding factor 3, RORC RAR-related orphan receptor C, FOXP forkhead box protein, TGF tumour growth factor, Th $\mathrm{T}$ helper cell, Treg T regulatory cell

Values are arbitrary units $\times 10^{4}$ relative to $\mathrm{EF} 1 \mathrm{a}$

Data are expressed as median (interquartile range)

Adjustments are selected backward stepwise from significant differences between groups (sex, rhinitis on the operation day, any respiratory symptoms on the operation day, operation made spring, operation made fall) and age

${ }^{*} \mathrm{n}=15$

$*^{*} \mathrm{n}=11$

and clinical data. The higher Tbet expression supports also the decline of RORC2 in $\mathrm{RV}-\mathrm{C}$ group being also in agreement with the findings of Glanville et al. [24]. RORC2 acts as a transcription factor for IL-17 which is involved in many inflammatory disorders [23].

The rate of respiratory symptoms on the operation day was fairly small (33\%) thus our patients are representing mostly asymptomatic subjects. More than half had symptoms 2 to 4 weeks prior the operation which might reflect virus shedding from a past symptomatic infection. It may take even 5-6 weeks from rhinovirus to disappear from nasal mucus [25]. Even in healthy children rhinovirus have been found in 15 to $35 \%$ in asymptomatic individuals $[2,20,21,26,27]$ giving an explanation of why only a small proportion of rhinovirus infected patients had symptoms on the operation day. Majority of the patients having respiratory symptoms on the operation day had RV-A or RV-C infection and only one had RV-B infection supporting the stronger clinical importance of RV-A and RV-C. 


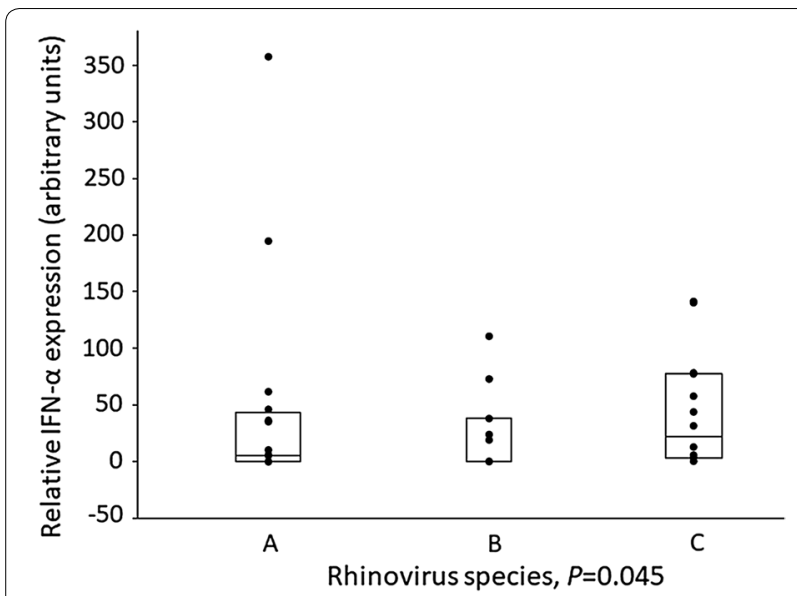

Fig. 2 Relative tonsillar expression of IFN-a. Comparison of tonsil samples between 16 RV-A, 12 RV-B and 14 RV-C positive patients (Table 3). Values are arbitrary units $\times 10^{4}$ relative to EF1a. Data represents median with interquartile range. The median of RV-B is 0.37. IFN, interferon

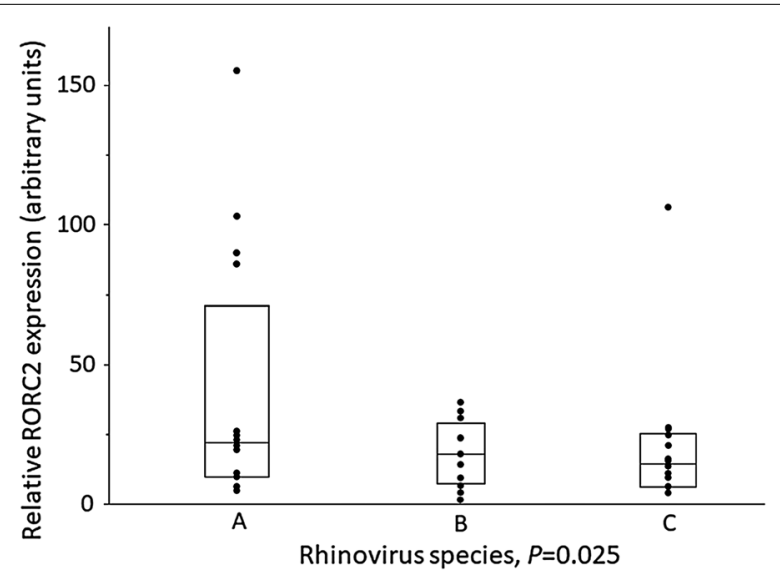

Fig. 3 Relative tonsillar expression of RORC2. Comparison of tonsil samples between 16 RV-A, 12 RV-B and 14 RV-C positive patients (Table 3). Values are arbitrary units $\times 10^{4}$ relative to EF1a. Data represents median with interquartile range. RORC2, RAR-related orphan receptor $\mathrm{C} 2$

The strength of the study was that it consisted relatively healthy tonsillectomy patients, and thereby our results suggest normal cytokine responses due to symptomatic or asymptomatics RV infection. Many previous studies concern hospitalized patients having an acute infection [7, 9, 14, 21, 28]. Also, our study population was constructed with both children and adults whereas often studies concern only children. We also used single cytokine PCR and patients as well as their preceding symptoms were well-characterized. There were also some limitations. Sample size was relatively small and because of subpopulation of study subjects the study was not

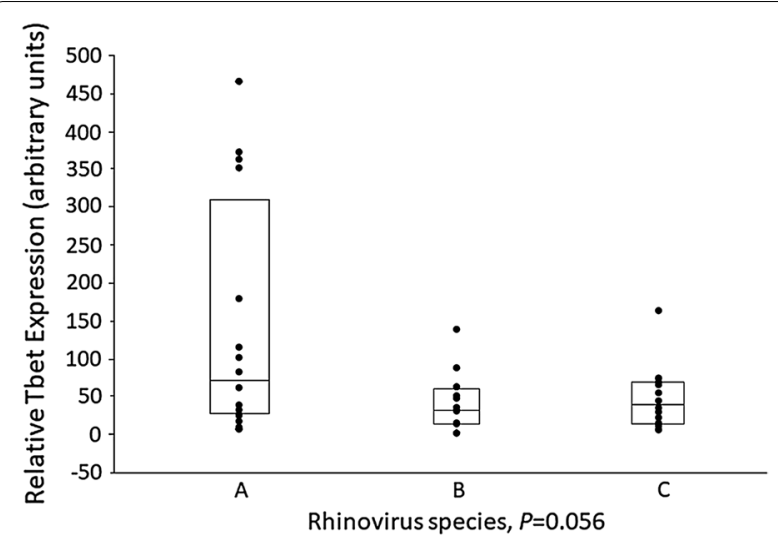

Fig. 4 Relative tonsillar expression of Tbet. Comparison of tonsil samples between 16 RV-A, 12 RV-B and 14 RV-C positive patients (Table 3). Values are arbitrary units $\times 10^{4}$ relative to EF1a. Data represents median with interquartile range. Tbet, T-box transcription factor

powered to detect significant changes in outcome measures. We studied only viruses, not bacteria. As there was no control group the observations are not clearly associated with the presence of an acute infection. Our results can only be generalized for healthy individuals. Then, the immune response due to RV-infection is a dynamic process and the relevance of history of previous RV infections remains obscure. The samples were taken at a single time point as the tonsils can be removed only once and therefore it is difficult to assess whether the observed changes were time-dependent or uniform over longer period of time.

\section{Conclusions}

To our best knowledge, this was the first time to study immune responses between rhinovirus species at the local lymphoid tissue level. We found that rhinovirus species were associated differently with clinical characteristics and tonsillar cytokine responses. The most interesting finding was the increase of IFN- $\alpha$ and Tbet and decrease of RORC2 in rhinovirus $\mathrm{C}$ affected patients suggesting that rhinovirus $\mathrm{C}$ infection has greater effect on tonsillar Th1 and Th17 responses than rhinovirus A or B infection. Our results encourage to study immune responses at the local lymphoid tissue level by using tonsils.

\section{Supplementary information}

Supplementary information accompanies this paper at https://doi. org/10.1186/s13601-019-0302-7.

Additional file 1: Table S1. Health questionnaire 


\section{Abbreviations}

AdV: adenovirus; CoV: coronavirus; EF1a: housekeeping elongation factor $1 \mathrm{a}$ EV: enterovirus; Flu: influenza virus; FOXP: forkhead box protein; GATA: GATAbinding factor; HBoV: human bocavirus; IFN: interferon; IgE: immunoglobulin E; IL: interleukin; IQR: interquartile range; MPV: metapneumovirus; NPS: nasopharyngeal aspirate; PCR: polymerase chain reaction; PIV: parainfluenza virus; RORC: RAR-related orphan receptor C; RNA: ribonucleic acid; RSV: respiratory syncytial virus; RUNX: runt-related transcription factor; RV: human rhinovirus; Tbet: T-box transcription factor; TGF: tumour growth factor; Th: T helper cell.

\section{Acknowledgements}

We thank laborant Heidi Jokinen (University of Turku) for her assistant in laboratory work, and statistician Tero Vahlberg (University of Turku), for his help in statistics.

\section{Authors' contributions}

The study protocol and manuscript were written by the investigators. Data were collected by TP, EM and LI and analyzed by EM, AS and TJ. Immunologic analyses were done by OP, RT and BR and supervised by MA and CA. Viral analyses were carried out by MW and TVu. The study was supervised by CA and TJ. The granting agencies covered all costs and played no role in study design, data analysis, or manuscript preparation. All authors read and approved the final manuscript.

\section{Funding}

T.J. and his laboratory are supported by the Academy of Finland (Grants 114034 and 132595), the Finnish Medical Foundation, the Sigrid Juselius Foundation, and the Foundation for Pediatric Research. E.M. is supported by the Finnish Cultural Foundation and the Allergy Research Foundation. O.P. laboratory is supported by grant SAF-2017-84978-R from MINECO. M.A.'s laboratory is sponsored by EU 7th Framework Program PREDICTA: Post-Infectious Immune Reprogramming and Its Association with Persistence and Chronicity of Respiratory Allergic Diseases (No: 260895). Laboratory of CA.A. is supported by the Swiss National Science Foundation Grant 32-132899 and Christine Kühne-Center for Allergy Research and Education.

\section{Availability of data and materials}

The datasets generated and analysed during the current study are not publicly available due to individual privacy but are available from the corresponding author on reasonable request.

\section{Ethics approval and consent to participate}

The study protocol was approved by the Ethics Committee of Satakunta Central Hospital. Written consent to participate in the study from the patient or his/her guardian was acquired.

\section{Consent for publication}

Not applicable.

\section{Competing interests}

The authors declare that they have no competing interests.

\begin{abstract}
Author details
${ }^{1}$ Department of Otorhinolaryngology, Turku University Hospital and University of Turku, Turku, Finland. ${ }^{2}$ Swiss Institute of Allergy and Asthma Research, University of Zürich, Davos, Switzerland. ${ }^{3}$ Christine Kühne-Center for Allergy Research and Education, Davos, Switzerland. ${ }^{4}$ Department of Biochemistry and Molecular Biology, School of Chemistry, Complutense University of Madrid, Madrid, Spain. ${ }^{5}$ Department of Pediatrics and Adolescent Medicine, Turku University Hospital and University of Turku, Turku, Finland. ${ }^{6}$ Clinical Microbiology, Turku University Hospital, Turku, Finland. ${ }^{7}$ Institute of Biomedicine, University of Turku, Turku, Finland. ${ }^{8}$ Department of Otorhinolaryngology, Satakunta Central Hospital, Sairaalantie 3, 28500 Pori, Finland. ${ }^{9}$ Children's Hospital, Helsinki University Hospital and University of Helsinki, Helsinki, Finland.
\end{abstract}

Received: 17 August 2019 Accepted: 22 November 2019

Published online: 02 December 2019

\section{References}

1. Jacobs SE, Lamson DM, St. George K, Walsh TJ. Human Rhinoviruses. Clin Microbiol Rev. 2013;26(1):135

2. Jartti T, Gern JE. Role of viral infections in the development and exacerbation of asthma in children. J Allergy Clin Immunol. 2017;140(4):895-906.

3. Lee WM, Kiesner C, Pappas T, Lee I, Grindle K, Jartti T, et al. A diverse group of previously unrecognized human rhinoviruses are common causes of respiratory illnesses in infants. PLoS ONE. 2007;2(10):e966.

4. Chen W, Arnold JC, Fairchok MP, Danaher PJ, McDonough EA, Blair PJ, et al Epidemiologic, clinical, and virologic characteristics of human rhinovirus infection among otherwise healthy children and adults: rhinovirus among adults and children. J Clin Virol. 2015;64:74-82.

5. Müller L, Mack I, Tapparel C, Kaiser L, Alves MP, Kieninger E, et al. Human rhinovirus types and association with respiratory symptoms during the first year of life. Pediatr Infect Dis J. 2015;34(8):907-9.

6. Gern JE. The ABCs of rhinoviruses, wheezing, and asthma. J Virol. 2010;84(15):7418-26.

7. Lauinger IL, Bible JM, Halligan EP, Bangalore $H$, Tosas $O$, Aarons EJ, et al. Patient characteristics and severity of human rhinovirus infections in children. J Clin Virol. 2013;58(1):216-20.

8. Stone CA Jr, Miller EK. Understanding the association of human rhinovirus with asthma. Clin Vaccine Immunol. 2016;23(1):6-10.

9. Ahn JG, Kim DS, Kim KH. Clinical characteristics and cytokine profiles of children with acute lower respiratory tract infections caused by human rhinovirus. PLOS ONE. 2018;13(7):e0198624.

10. Nakagome K, Bochkov YA, Ashraf S, Brockman-Schneider RA, Evans MD, Pasic TR, Gern JE. Effects of rhinovirus species on viral replication and cytokine production. J Allergy Clin Immunol. 2014;134(2):341.e10.

11. Jartti T, Palomares $\mathrm{O}$, Waris $\mathrm{M}$, Tastan $\mathrm{O}$, Nieminen R, Puhakka T, et al. Distinct regulation of tonsillar immune response in virus infection. Allergy. 2014:69(5):658-67.

12. Mikola E, Elenius V, Saarinen M, Palomares $O$, Waris M, Turunen R, et al. Tonsillar cytokine expression between patients with tonsillar hypertrophy and recurrent tonsillitis. Clin Transl Allergy. 2018;8(1):22.

13. Elenius $V$, Palomares $O$, Waris $M$, Turunen $R$, Puhakka T, Rückert $B$, et al. The relationship of serum vitamins A, D, E and LL-37 levels with allergic status, tonsillar virus detection and immune response. PLOS ONE. 2017; 12(2):e0172350

14. Turunen R, Jartti T, Bochkov YA, Gern JE, Vuorinen T. Rhinovirus species and clinical characteristics in the first wheezing episode in children. J Med Virol. 2016;88(12):2059-68.

15. Turunen R, Vuorinen T, Bochkov Y, Gern J, Jartti T. Clinical and virus surveillance after the first wheezing episode: special reference to rhinovirus $A$ and C species. Pediatr Infect Dis J. 2017;36(6):539-44.

16. Morikawa S, Kohdera U, Hosaka T, Ishii K, Akagawa S, Hiroi S, Kase T. Seasonal variations of respiratory viruses and etiology of human rhinovirus infection in children. J Clin Virol. 2015;73:14-9.

17. Scotta MC, Chakr VC, de Moura A, Becker RG, de Souza AP, Jones MH, et al. Respiratory viral coinfection and disease severity in children: a systematic review and meta-analysis. J Clin Virol. 2016;80:45-56.

18. Miller EK, Edwards KM, Weinberg GA, Iwane MK, Griffin MR, Hall CB, et al. A novel group of rhinoviruses is associated with asthma hospitalizations. J Allergy Clin Immunol. 2009;123(1):104.e1.

19. Pali-Schöll I, Jensen-Jarolim E. Gender aspects in food allergy. Curr Opin Allergy Clin Immunol. 2019;19(3):249-55.

20. Peltola V, Waris M, Österback R, Susi P, Hyypiä T, Ruuskanen O. Clinical effects of rhinovirus infections. J Clin Virol. 2008;43(4):411-4.

21. Hayden FG. Rhinovirus and the lower respiratory tract. Rev Med Virol. 2004;14(1):17-31.

22. Mcnab F, Mayer-Barber $K$, Sher A, Wack A, O'garra A. Type I interferons in infectious disease. Nat Rev Immunol. 2015;15(2):87-103.

23. Akdis M, Burgler S, Crameri R, Eiwegger T, Fujita H, Gomez E, et al. Interleukins, from 1 to 37, and interferon-g: receptors, functions, and roles in diseases. J Allergy Clin Immunol. 2011;127(3):701-21.

24. Glanville N, Peel TJ, Schröder A, Aniscenko J, Walton RP, Finotto S, et al. Tbet deficiency causes Thelper cell dependent airways eosinophilia and mucus hypersecretion in response to rhinovirus infection. PLoS Pathog. 2016:12(9):e1005913. 
25. Jartti T, Lehtinen P Vuorinen T, Koskenvuo M Ruuskanen O. Persistence of rhinovirus and enterovirus RNA after acute respiratory illness in children. J Med Virol. 2004;72(4):695-9.

26. Iwasaki J, Smith WA, Khoo SK, Bizzintino J, Zhang G, Cox DW, et al. Comparison of rhinovirus antibody titers in children with asthma exacerbations and species-specific rhinovirus infection. J Allergy Clin Immunol. 2014;134(1):32.e1

27. van der Zalm MM, Wilbrink B, van Ewijk BE, Overduin P, Wolfs TF, van der Ent CK. Highly frequent infections with human rhinovirus in healthy young children: a longitudinal cohort study. J Clin Virol. 2011:52(4):317-20.
28. Turunen R, Koistinen A Vuorinen T, Arku B, Söderlund-Venermo M, Ruuskanen $\mathrm{O}$, et al. The first wheezing episode: respiratory virus etiology, atopic characteristics, and illness severity. Pediatr Allergy Immunol. 2014;25(8):796-803

\section{Publisher's Note}

Springer Nature remains neutral with regard to jurisdictional claims in published maps and institutional affiliations.
Ready to submit your research? Choose BMC and benefit from:

- fast, convenient online submission

- thorough peer review by experienced researchers in your field

- rapid publication on acceptance

- support for research data, including large and complex data types

- gold Open Access which fosters wider collaboration and increased citations

- maximum visibility for your research: over $100 \mathrm{M}$ website views per year

At BMC, research is always in progress.

Learn more biomedcentral.com/submissions 